\title{
A kidney tumor to know: mucinous tubular and spindle cell carcinoma of the kidney (mtscc-k)
}

\author{
Y. Dehayni ${ }^{1}$, Y. Elabiad ${ }^{1}$, B. Balla ${ }^{1}$, Y. Boukhlifi ${ }^{1}$, H. Benomar ${ }^{1}$, A. Ammani ${ }^{2}$, A. Qarro ${ }^{2}$ and M. Alami $^{2}$ \\ ${ }^{1}$ Department of Urology, Military hospital Moulay Ismail, Meknès, Morocco. \\ ${ }^{2}$ Department of Urology Sidi Mohammed Ben Abdellah University, Fes, Morocco
}

\begin{abstract}
Mucinous tubular and spindle cell carcinoma of the kidney (MTSCC K) is an unusual renal tumor. It is important to increase the recognition of MTSCC K and improve the level of clinical diagnosis. We report a case of mucinous tubular and spindle cell carcinoma in a 50-year old woman. The tumour, located on the left kidney, was well circumscribed and a partial nephrectomy was applied. In microscopically, the tumour was composed of cuboidal cells arranged in tubules and was making abrupt transitions to the spindle cell morphology in a myxoid stroma. Due to it's favourable prognosis, mucinous tubular and spindle cell carcinoma must be differentiated from papillary renal cell carcinoma, especially that with sarcomatoid change.
\end{abstract}

\section{Introduction}

Mucinous tubular and spindle cell carcinoma of the kidney (MTSCC-K) is a rare renal epithelial tumor, believed to be a type of low-grade malignant tumor. The precise origin is unclear, certain researchers have hypothesised that it originates from the loop of Henle or the distal tubule. However, the majority of researchers hypothesise that its origin is in the distal tubule [1].

MTSCC-K is difficult to pathologically differentiate from highgrade malignant renal tumors, including collecting duct carcinoma and sarcomatoid carcinoma. It was first reported in 1997 by MacLennan et al and was known as a 'low-grade collecting duct carcinoma' [2].

It was introduced in the latest WHO classification of renal tumors in 2004 as a separate entity [3]. Through a new case and literature review, we discuss the histological features of the tumor as well as the differential diagnosis.

\section{Case report}

We report a new case in a 50-year-old woman presented with a 3-month history of left flank pain without gross hematuria and fever. The Renal function test results were normal, and without history of stone disease.

Hypovascular renal masse were noted on ultrasonography, and the imaging examination by abdominal computed tomography (CT) scan revealed a $7 \mathrm{x} 5-\mathrm{cm}$ well-circumscribed solid mass, and protruding outside the renal contour in the superior pole of the left kidney.The CT was performed initially to obtain baseline attenuation values of lesions and to identify calcification with no clear enhancement identified in the corticomedullary phase. However, marginal uneven enhancement was observed in the nephrographic phase (Figure 1).

No metastasis was identified to the retroperitoneal lymph node, abdominal organs or lungs. The patient provided written informed consent.

The patient underwent partial nephrectomy resection of the left kidney by a left subcostal incision. No postoperative therapy was given to the patient.

Macroscopy: Dissection of the specimen revealed that the tumor was well-circumscribed, solid and grayish yellow in appearance, measuring $4.5 \times 3.5 \times 3.5 \mathrm{~cm}$. No areas of hemorrhage were identified in the tumor. Unlike necrosis zones have been identified.
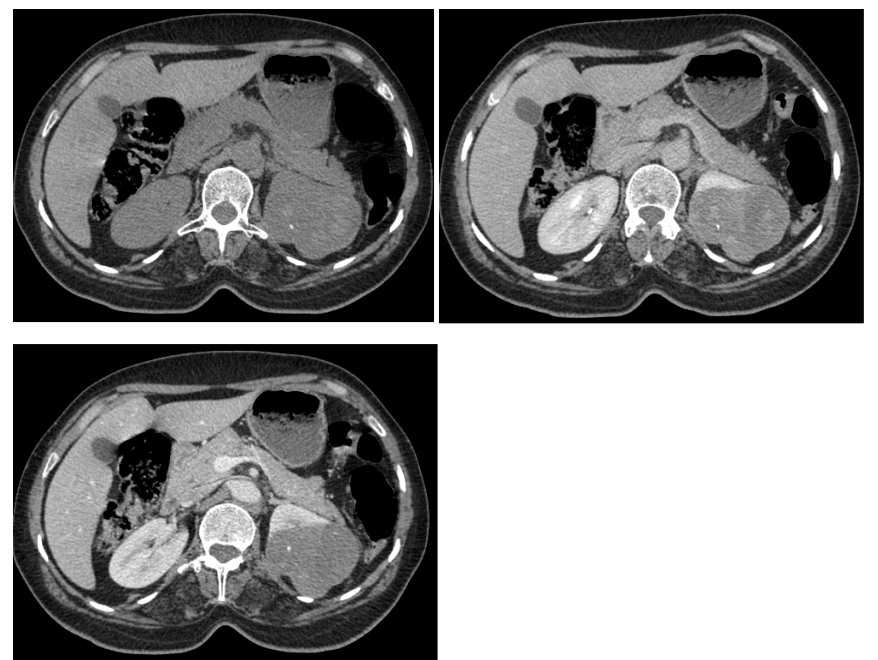

Figure 1. Contrast enhanced abdominal CT scan. It revealed a tumor on the superior pole of the kidney, and demonstrated the tumor was slightly enhanced on the corticomedullary phase and nephrographic phase

Correspondence to: Y. Dehayni, Department of Urology, Military hospital Moulay Ismail, Meknès, Morocco, E-mail: dr.y.dehayni@gmail.com

Key words: mucinous tubular and spindle cell carcinoma, kidney, computed tomography, partial nephrectomy

Received: October 27, 2016; Accepted: November 23, 2016; Published: November 25, 2016 
Microscopy: The tumor was composed of small, elongated cords or tubules, in a tightly packed arrangement. Myxoid stroma was shown to be interspersed among the tubular cells, and appeared to exhibit slender tubular spindle cell-like structures. Tumor cells were smaller and cubic-shaped or oval, with single small eosinophilic nucleoli and low-grade nuclei. Occasionally, necrosis and foam cell infiltration were identified. The myxoid stroma was stained by acidic mucus (Figure 2).

\section{Discussion}

Mucinous tubular and spindle cell carcinoma is a rare, malignant renal epithelial tumor which showed a female predominance and favorable prognosis. Further, it has been recognized as a new entity of Renal Cell Carcinoma (RCC) in 2004, and usually behaved in a lowgrade fashion [4]. More than 80 cases have been reported and not much is known about this tumor [5].

MTSCC-K has a wide age distribution, with an age range between 17 and 82 years and a mean age of 53 years. The female incidence is approximately three- or four-fold that of males [6-8].

Typically, the majority of patients present with asymptomatic masses were often found incidentally by ultrasound $[9,10]$. In a few cases, the patient may present us with flank pain or hematuria [9].

However, the clinical symptoms and imaging characteristics of the MTSCC-K are similar to the more common renal cell carcinoma (RCC). Therefore, a clear preoperative diagnosis becomes more difficult [11].

The current case underwent abdominal CT scan prior to surgery and no clear enhancement was identified in the arterial phase. However, marginal uneven enhancement was identified in the venous phase. This change is consistent with the previous literature and may provide references for the preoperative clinical diagnosis of MTSCC-K. In addition, it has been reported that fine needle aspiration biopsy may be diagnostic of MTSCC-K, which may aid to improve preoperative diagnosis rates [12].

Therefore, the true origin of MTSCC-K still requires further exploration. However, Hes et al. suggested that development of MTSCC-K could be related to a kidney stone, because of the total 11 cases they reported, three patients had kidney stone history and regional lymph node metastasis occurred in one patient $[13,14]$.

In microscopically, multiple small and elongated branches arranged cord-likely tumor cells could be observed in lightly stained myxoid stroma and area of spindle cells could also be observed. Periodic acid Schiff (PAS) staining shows that the tubular was surrounded by the

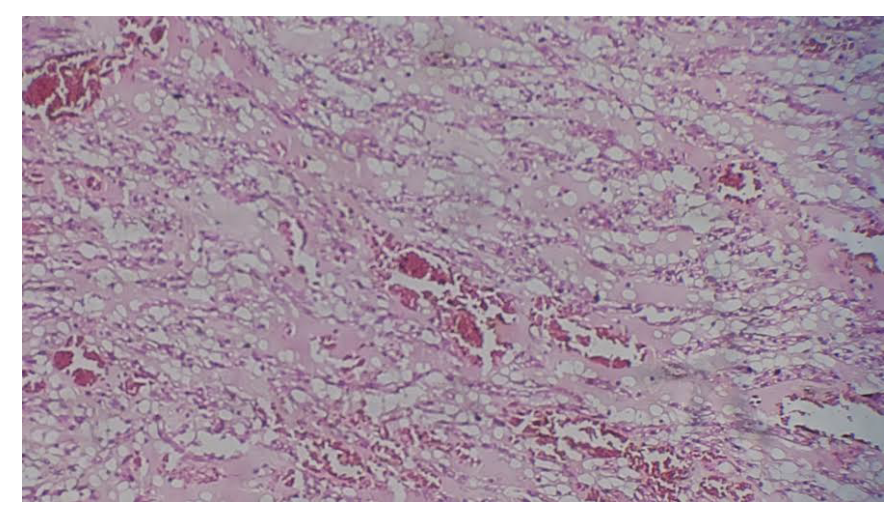

Figure 2. Tumor was composed of small, elongated cords or tubules, in a tightly packed arrangement (hematoxylin and eosin; magnification, x20). basilar membrane. The tumor cell is small with a cubic or oval shape with less cytoplasm that is transparent, pale and acidophilus. The nuclear grade of the tumor is usually low and the size of nucleolus was low to medium. Necrosis is occasionally observed, with foam cell infiltration and chronic inflammatory cell infiltration being common. Myxoid stroma staining revealed acidic mucus with positive Alcian blue [15].

Previously, Fine et al. [14] described the histological types of MTSCC-K and divided them into the following two categories: Classic, abundance of extracellular mucin stroma; and mucin-poor, little to no extracellular mucin. In addition, the unusual organizational characteristics associated with MTSCC-K are as follows: Papillary clear cell structure, necrosis, ectopic bone or grit-like calcospherites and neuroendocrine differentiation has also been reported [16,17].

This tumor can also be confused with the papillary RCC that has sarcomatoid change, but in the MTSCC-K, spindle cells are arranged in parallel bundles with eosinophilic cytoplasm and low-grade nuclei [18].

In cytogenetic studies, genetic abnormalities found in MTSCC-K cells are monosomies in chromosomes 1, 4, 6, 8 and 13, and total or partial trisomies of chromosomes 7, 11, 16 and 17 [6].

Immunohistochemistry is not helpful in discriminating between papillary RCC and MTSCC-K because the morphological interpretation is sufficient in the distinction between these tumors.

However, Cytokeratin CK7 and CK19, and Rcc could be expressed in both MTSCC-K and renal cell carcinoma. Further, CD10 is lowly expressed in MTSpCC, indicating that CD10 may be a useful marker to differentially diagnose these tumors $[19,20]$.

\section{Conclusion}

Overall, MTSCC-K exhibits a lower malignant degree and an improved prognosis compared with other types of RCC. In summary, mucinous tubular and spindle cell carcinoma is a rare and only recently described distinctive subtype of renal cell carcinoma. It must be differentiated from papillary renal cell carcinoma, especially with sarcomatoid change, which has a much weaker prognosis.

\section{Ethical standards}

I declare that all procedures followed during this research experiment comply with the highest local ethical standards.

\section{Conflict of interest}

Youness Dehayni, Mohamed Sinaa, Yassine Elabiad, Bouzid Balla, Abdelghani Ammani, Abdelmounaim Qarro and Mohamed Alami declare that they do not have any conflicts of interest.

\section{References}

1. Jung SJ, Yoon HK, Chung JI, Ayala AG, Ro JY (2006) Mucinous tubular and spindle cell carcinoma of the kidney with neuroendocrine differentiation: report of two cases. Am J Clin Pathol 125: 99-104. [Crossref]

2. MacLennan GT, Farrow GM, Bostwick DG (1997) Low grade collecting duct carcinoma of the kidney: report of 13 cases of low grade mucinous tubulocystic renal carcinoma of possible collecting duct origin. Urology 50: 679-684.

3. WHO classification of tumors Lyon: IARC Press.

4. Lopez-Beltran A, Scarpelli M, Montironi R, Kirkali Z (2006) 2004 WHO classification of the renal tumors of the adults. Eur Urol 49: 798-805. [Crossref]

5. Yang G, Breyer BN, Weiss DA, MacLennan GT (2010) Mucinous tubular and spindle cell carcinoma of the kidney. J Urol 183: 738-739. [Crossref] 
6. Fine SW, Argani P, DeMarzo AM, Delahunt B, Sebo TJ, et al. (2006) Expanding the histologic spectrum of mucinous tubular and spindle cell carcinoma of the kidney. $\mathrm{Am}$ J Surg Pathol 30: 1554-1560. [Crossref]

7. MacLennan GT, Cheng L (2008) Neoplasms of the kidney. In: Urologic Surgical Pathology. Bostwick DG and Cheng L (eds). 2nd edition. Mosby Elsevier, Philadelphia, PA.

8. Srigley JR (2004) Tumors of the kidney: Mucinous tubular and indle cell carcinoma. In: Pathology and Genetics of tumours of the Urinary System and Male Genital Organs. Eble JN, Sauter G, Epstein JI and Sesterhenn IA (eds). IARC Press, Lyon.

9. Eble JN (2003) Mucinous tubular and spindle cell carcinoma and post neuroblastoma carcinoma: newly recognised entities in the renal cell carcinoma family. Pathology 35: 499-504.

10. Eble JN, Young RH (2007) Tumors of the urinary tract. In: Diagnostic Histopathology of Tumors. Fletcher CDM (ed), 3rd edition. Churchill Livingstone, Edinburgh.

11. Sun N, Fu Y, Wang Y, Tian T, An W, et al. (2014) Mucinous tubular and spindle cell carcinoma of the kidney: A case report and review of the literature. Oncol Lett 7: 811814. [Crossref]

12. Marks Jones DA, Zynger DL, Parwani AV, Cai G (2010) Fine needle aspiration biopsy of renal mucinous tubular and spindle cell carcinoma: report of two cases. Diagn Cytopatho 38: 51-55.

13. Ferlicot S, Allory Y, Compérat E, Mege-Lechevalier F, Dimet S, et al. (2005) Mucinous tubular and spindle cell carcinoma: a report of 15 cases and a review of the literature. Virchows Arch 447: 978-983. [Crossref]
14. Hes O, Hora M, Perez-Montiel DM (2002) Spindle and cuboidal renal cell carcinoma, a tumor having frequent association with nephrolithiasis: a re $\neg$ port of 11 cases including a case with hybrid conventional renal cell carcinoma/spindle and cuboidal renal cell carcinoma components. Histopathology 41: 549- 555.

15. Chen Q, Gu Y, Liu B (2015) Clinicopathological characteristics of kidney mucinous tubular and spindle cell carcinoma. Int J Clin Exp Pathol 8: 1007-1012. [Crossref]

16. Fine SW, Argani P, DeMarzo AM, Delahunt B, Sebo TJ, et al. (2006) Expanding the histologic spectrum of mucinous tubular and spindle cell carcinoma of the kidney. $\mathrm{Am}$ J Surg Pathol 30: 1554-1560. [Crossref]

17. Paner GP, Srigley JR, Radhakfishnan A (2006) Immunohistochemical analysis of mucinous tubular and spindle cell carcinoma and papillary renal cell carcinoma of the kidney: significant immuno $\neg$ phenotypic overlap warrants diagnostic caution. $\mathrm{Am} \mathrm{J}$ Surg Pathol 30: 13-19.

18. Fleming S (2005) Recently recognized epithelial tumours of the kidney. Curr Diagn Pathol 11:162-169.

19. Sarsik B, Sımşır A, Karaarslan S, Sen S (2011) Mucinous tubular and spindle cell carcinoma of kidney and problems in diagnosis. Turk Patoloji Derg 27: 116-126. [Crossref]

20. Cheong H, Ro Jae Y, Monzon Federico A (2010) Muci $\neg$ nous tubular and spindle cell carcinoma of the kidney: A distinct morphologic entity of renal cell carcinoma. Pathol Case Rev 15: 7-10.

Copyright: (C2016 Dehayni Y. This is an open-access article distributed under the terms of the Creative Commons Attribution License, which permits unrestricted use, distribution, and reproduction in any medium, provided the original author and source are credited. 